\title{
Increased proportions of outdoor feeding among residual malaria vector populations following increased use of insecticide-treated nets in rural Tanzania
}

Tanya L Russell ${ }^{1,2,3^{*}}$, Nicodem J Govella ${ }^{1,2}$, Salum Azizi ${ }^{1}$, Christopher J Drakeley ${ }^{4}$, S Patrick Kachur ${ }^{5}$ and Gerry F Killeen ${ }^{1,2}$

\begin{abstract}
Background: Insecticide-treated nets (ITNs) and indoor residual spraying (IRS) represent the front-line tools for malaria vector control globally, but are optimally effective where the majority of baseline transmission occurs indoors. In the surveyed area of rural southern Tanzania, bed net use steadily increased over the last decade, reducing malaria transmission intensity by $94 \%$.

Methods: Starting before bed nets were introduced (1997), and then after two milestones of net use had been reached-75\% community-wide use of untreated nets (2004) and then $47 \%$ use of ITNs (2009)-hourly biting rates of malaria vectors from the Anopheles gambiae complex and Anopheles funestus group were surveyed.

Results: In 1997, An. gambiae s.l. and An. funestus mosquitoes exhibited a tendency to bite humans inside houses late at night. For An. gambiae s.l., by 2009, nocturnal activity was less ( $p=0.0018$ ). At this time, the sibling species composition of the complex had shifted from predominantly An. gambiae s.s. to predominantly An. arabiensis. For An. funestus, by 2009, nocturnal activity was less $(p=0.0054)$ as well as the proportion biting indoors $(p<0.0001)$. At this time, An. funestus s.s. remained the predominant species within this group. As a consequence of these altered feeding patterns, the proportion (mean \pm standard error) of human contact with mosquitoes (bites per person per night) occurring indoors dropped from $0.99 \pm 0.002$ in 1997 to $0.82 \pm 0.008$ in 2009 for the An. gambiae complex ( $p=0.0143$ ) and from $1.00 \pm<0.001$ to only $0.50 \pm 0.048$ for the An. funestus complex $(p=0.0004)$ over the same time period.

Conclusions: High usage of ITNs can dramatically alter African vector populations so that intense, predominantly indoor transmission is replaced by greatly lowered residual transmission, a greater proportion of which occurs outdoors. Regardless of the underlying mechanism, the residual, self-sustaining transmission will respond poorly to further insecticidal measures within houses. Additional vector control tools which target outdoor biting mosquitoes at the adult or immature stages are required to complement ITNs and IRS.
\end{abstract}

\section{Background}

Millennia of co-evolution between humans, mosquitoes and malaria parasites have resulted in a highly specialized and efficient system for malaria transmission in Africa [1]. The principal African malaria vectors from the Anopheles gambiae complex and the Anopheles

\footnotetext{
* Correspondence: t.russell2@uq.edu.au

'Ifakara Health Institute, Biomedical and Environmental Thematic Group, P.O, Box 53, Ifakara, Tanzania

Full list of author information is available at the end of the article
}

funestus group feed almost exclusively indoors at night, on sleeping humans [2-4]. This highly specialized feeding behaviour led to the development of effective frontline vector control tools-insecticide-treated nets (ITNs) and indoor residual spraying (IRS)-that target insecticide to human habitations $[2,4,5]$. Wide-spread use of ITNs, which reduces the density, feeding frequency and survival of mosquitoes at the population level by killing mosquitoes with insecticide or blocking their contact with humans [6-9], can protect all community members,

\section{Biomed Central}


even those not using a net [10-13]. In recent years, the number of success stories associated with wide-scale ITN use has increased and the incidence of malaria has begun to decline in many parts of Africa [14-16].

As the international community has now prioritized national and regional elimination with a long-term ultimate goal of malaria eradication [17], the need to understand the biological implications of wide-spread and long-term ITN use is paramount. Understanding the ecological and epidemiological characteristics of residual malaria transmission will be essential to adjust intervention strategies, as frontline tactics shift importance from primary to presently-secondary sources of transmission as the programme approaches elimination. The current study is a retrospective analysis, examining the impact of prolonged and wide-spread ITN pressure on the feeding patterns of anopheline mosquito populations in East Africa. Shifts in vector feeding patterns to avoid intradomicilary vector control tools would be accompanied by shifts in the importance of various sources of transmission; for example, mosquito populations feeding more outside at dusk or dawn would be responsible for proportionally more transmission events. It was hypothesized that wide-scale ITN use would precipitate a change in the vector population, investigating possible shifts in human-biting time or location over a 12-year period.

\section{Methods}

\section{Study area}

The study was conducted in the Kilombero Valley $\left(8.1^{\circ} \mathrm{S}\right.$ and $36.6^{\circ} \mathrm{E}$ ) in south-eastern Tanzania. The communities experience hyper-endemic malaria transmission [18], with a peak during the main rainy season (March May), when larval habitat area expands. The primary vectors are from the Anopheles gambiae sensu lato (s.l.) complex, which is represented by two behaviourally distinctive species: An. gambiae sensu stricto (s.s.) and Anopheles arabiensis [19]. A third, locally important vector species is $A n$. funestus s.s., which belongs to the $A n$. funestus group.

The ecosystem of the Kilombero Valley is dominated by a low lying river valley, $150 \mathrm{~km}$ long and up to 40 $\mathrm{km}$ wide, which is inter-dispersed with villages and rice farms. During the current study, mosquitoes were collected from two villages (Njagi and Lupiro), both situated on the valley floor and with similar ecosystems (Figure 1). Recent genetic research indicates mosquito population structuring in the Kilombero Valley is associated with ecological complexity, opposed to geographical distance. Thus, mosquito samples from Njagi and Lupiro villages would represent one interbreeding, genetically homogenous population of An. gambiae s.l., even though the villages are situated on opposing sides of the Kilombero Valley [20].

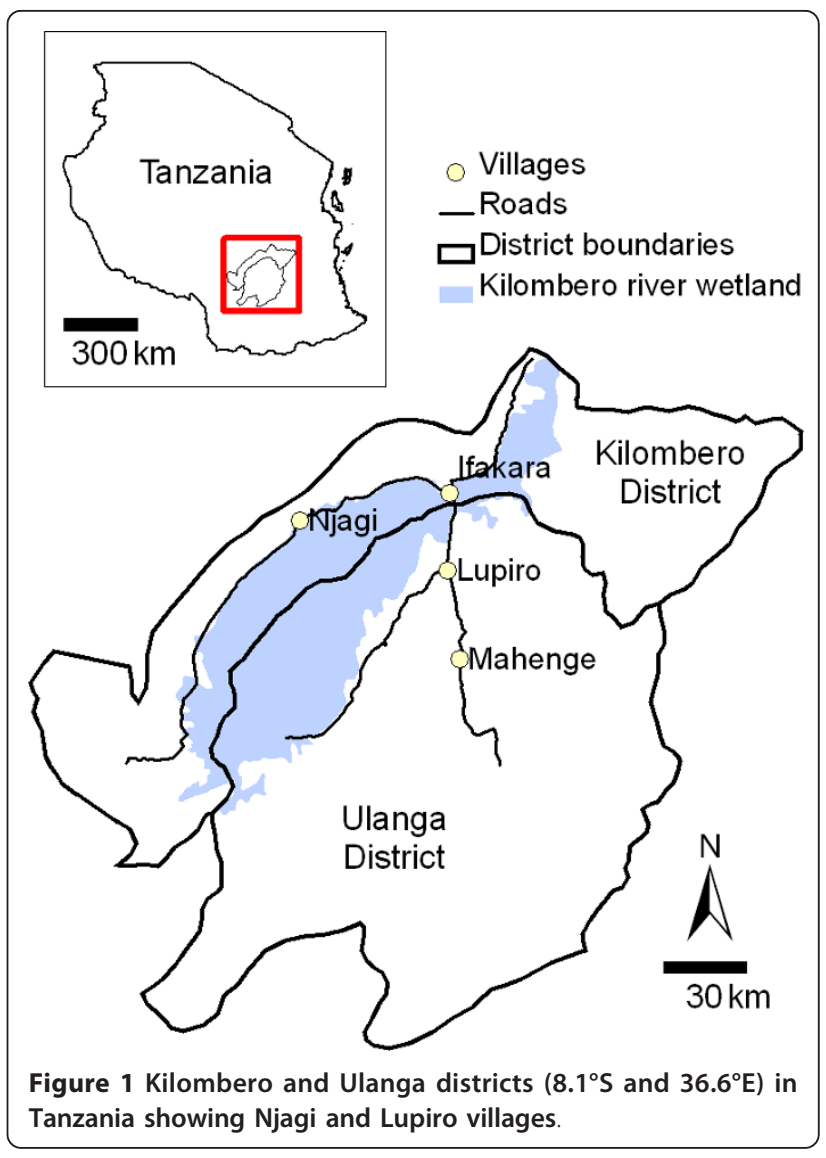

A successful cost-sharing scheme for subsidising and promoting bed nets and home insecticide treatment kits was initiated in 1999 in an effort to alleviate the malaria burden [18] and this scheme was eventually adopted at national level in 2000 [21], resulting in steadily increasing coverage of nets and then insecticide treatments over the last decade [22]. While no ITN surveys were conducted in 1997 (when the first entomological survey was conducted), by the start of the first valley-wide ITN promotion scheme in 1999, demographic surveillance system (DSS) surveys of $>60,000$ people revealed that $<10 \%$ of people owned a bed net [18]. Subsequent surveys through the same DSS platform were conducted annually to estimate usage of both untreated and treated nets [22].

\section{Study design}

The indoor and outdoor biting profiles of An. gambiae s.l. and the An. funestus group were estimated using human landing catches (HLC) in Nov 1997, Jul/Aug 2004 and May/Jun 2009. The estimates for 1997 represent mosquito behaviour before ITN use became widespread, 2004 was after $75 \%$ community-wide use of untreated bed nets had been achieved and 2009 was after $47 \%$ use of ITNs and $91 \%$ use of any net had been 
reached a year previously [22]. The 1997 vector behaviour survey was conducted in Njagi village $[23,24]$ whereas the 2004 and 2009 surveys were conducted in Lupiro village [3].

To conduct HLC, male volunteers sat with their legs exposed and caught mosquitoes that came to bite them with an aspirator [25]. Mosquitoes were caught for 45 min each hour, allowing 15 min break for rest. Catches were conducted between 19.00 and $07.00 \mathrm{hrs}$. The catches for each hourly interval were stored in separate collection cups.

The experimental details for the 1997 and 2004 surveys are described in Killeen et al [3]. Regarding the 2009 survey, each replicate collection of mosquitoes was made from an experimental unit that consisted of one experimental hut (simulating an average home) [26] and one outdoor sampling station situated $10 \mathrm{~m}$ from the hut. Each experimental hut contained two people and two untreated bed nets. Each experimental unit was separated by a distance of $\geq 30 \mathrm{~m}$ on flat land cleared of tall grass and other vegetation. One catcher caught mosquitoes in the outdoor station and another catcher simultaneously caught mosquitoes inside the experimental hut, the other person inside the hut was asleep under the bed net. There were four experimental units in total and on each night collections were made from one. Each night, the collectors were systematically rotated through the four of the experimental units using a Latin square design, to minimize biases due to individual odour or geographic location. The survey was conducted for 20 consecutive nights in June 2009.

All anopheline mosquitoes were morphologically identified to sex and species or species complex then visually classified as being unfed, partially fed, fully fed or gravid [27,28]. Throughout the 2009 survey, subsamples of up to nine individual mosquitoes were taken from each trap to determine sibling species identity within the An. gambiae s.l. complex using PCR [29]. Prior to molecular analysis, individual mosquitoes were stored at $-20^{\circ} \mathrm{C}$ in micro-centrifuge tubes containing a small amount of silica drying agent separated from the mosquito by a thin layer of cotton. For statistical analysis, a longitudinal dataset of An. gambiae s.l. sibling species composition was constructed for Lupiro village using all published literature [19,26,30-34] as well as unpublished data held at the Ifakara Health Institute (IHI). The small numbers of An. funestus complex mosquitoes caught during the 2009 data collection were discarded; however, subsequent indoor catches in the same experimental huts obtained specimens which were used to determine the sibling species composition of this complex in Lupiro immediately after that period using PCR [35].

\section{Human behavioural surveys}

The behaviour of the human population during night times was estimated from answers to questionnaires, collected from 398 households between 2002 and 2004 [3]. The household members were asked what time they usually went to bed and arose in the morning.

\section{Estimating proportion of human contact with malaria vector bites occurring indoors}

The behavioural characteristics of the vector populations were compared using two entomological parameters: propensity to bite indoors (referred to as endophagy) and propensity to bite during the night when people usually sleep (referred to as nocturnality). Endophagy was calculated as the proportion of mosquitoes biting indoors as follows: $\mathrm{I}_{18 \rightarrow 06} \mathrm{hrs} /\left(\mathrm{I}_{18 \rightarrow 06} \mathrm{hrs}+\mathrm{O}_{18 \rightarrow 06} \mathrm{hrs}\right)$; where $\mathrm{I}=$ the total number of mosquitoes caught indoors, $\mathrm{O}=$ the total number of mosquitoes caught outdoors and the subscripts represent the start time for each hour [36]. Nocturnality was calculated as the proportion of mosquitoes biting either indoors or outdoors during peak sleeping hours (hours starting $9 \mathrm{pm}$ to 5 am) as follows: $\left(\mathrm{I}_{21 \rightarrow 05} \mathrm{hrs}+\mathrm{O}_{21 \rightarrow 05 \mathrm{hrs}}\right) /\left(\mathrm{I}_{18 \rightarrow 06} \mathrm{hrs}+\right.$ $\mathrm{O}_{18 \rightarrow 06}$ hrs) [36]. Additionally, the proportion of human contact with mosquito bites occurring indoors $\left(\pi_{\mathrm{i}}\right)$ was calculated by taking into consideration the movement pattern of people using two methods: (A) by weighting the mean indoor and outdoor biting rates throughout the night by the proportion of humans that are typically indoors or outdoors at each time period: $\pi_{i}=\sum\left[I_{t} S_{t}\right] /$ $\Sigma\left[O_{t}\left(1-S_{t}\right)\right]+I_{t} S_{t}$; where $\mathrm{S}=$ the proportion of humans indoors [see reference 3 for more detail] and (B) by using a simple binomial formula which assumes all humans go indoors at exactly $2100 \mathrm{hrs}$ and leave the house again at $0500 \mathrm{hrs:} \pi_{\mathrm{i}}=\mathrm{I}_{21 \rightarrow 05 \mathrm{hrs}} /\left(\mathrm{I}_{21 \rightarrow 05} \mathrm{hrs}+\right.$ $\mathrm{O}_{18,19,20,06 \mathrm{hrs}}$ ) [36].

\section{Statistical analysis}

Statistical changes in endophagy, nocturnal activity and the binomial estimate of human contact were compared over time using generalized linear mixed models (GLMM) with a binomial distribution, a categorical explanatory variable for study year and random factors for household nested within date. For each dependent factor, a binary dataset was constructed (using the formulas detailed above) to contain the number of mosquito bites (bites per person per night $[\mathrm{b} / \mathrm{p} / \mathrm{n}]$ ) that occurred indoors and outdoors for each date $\times$ household combination. Longitudinal statistical changes in An. gambiae s.l. sibling species composition (binary dependent variable) were analysed using a generalized linear model (GLM) with a binomial distribution and explanatory factors for year and rainfall. Rainfall was incorporated to account for the possibility that climate 
change had altered long-term precipitation patterns; this could be an important confounder as $A n$. arabiensis tends to be associated with relatively drier habitats [37]. The longitudinal rainfall data (2002-2009) was obtained from the nearby Kilombero Agricultural Training and Research Institute. All analyses were conducted using $R$, ver.2.9.1 [38].

\section{Ethics}

Ethical approval for the study was obtained from the IHI Institutional Review Board (IHI/IRB/No. A50), the Medical Research Coordination Committee of the National Institute for Medical Research (NIMR/HQ/ R.8a/Vol. IX/801) in Tanzania, and the Liverpool School of Tropical Medicine (09.60). Before the study commenced, written permission was obtained from each volunteer, who was informed, orally and via provision of a pamphlet about the potential risks and benefits of participating. After consenting, each volunteer was screened for malaria infection using microscopy and only malariafree individuals were allowed to participate. All volunteers were administered daily prophylaxis (Malarone ${ }^{\circledR}$, $250 \mathrm{mg}$ atovaquone and $100 \mathrm{mg}$ proguanil hydrochloride, GlaxoSmithKline) to prevent malaria infection during the course of the experiment. In addition, ready access to diagnosis and, if necessary, treatment (Coartem $^{\circledR}, 80 \mathrm{mg}$ artemether and $480 \mathrm{mg}$ lumefantrine over three days, Novartis Pharmaceuticals) was provided throughout the study.

\section{Results}

By 2009 , after $47 \%$ use of long-lasting insecticide-treated nets, the biting profiles of An. gambiae s.l. and the An. funestus group had diverged from those observed 12 years earlier (Figure 2; Table 1). Regarding $A n$. gambiae s.l. in 1997 this species exhibited a tendency to bite inside houses, late at night. By 2009, the proportion biting indoors $(\mathrm{b} / \mathrm{p} / \mathrm{n})$ was not significantly different at $57.5 \%$ (Table 1). However, their nocturnal activity was significantly less and consistent activity was observed throughout the night (Figure 2; Table 1). Regarding An. funestus, in 1997 this species exhibited endophagic and nocturnal behaviour. By 2009, the tendency for $A n$. funestus to bite indoors had significantly disappeared with less biting indoors than outdoors (Table 1). At this time, the nocturnality of An. funestus had also reduced (Table 1) and a peak in biting activity was recorded outdoors and early in the evening (Figure 2).

Most importantly, significant changes in the proportion of human contact with mosquito bites occurring indoors were recorded for both of these important vector taxa (Figure 3; Table 2). After adjusting for the typical movement of people, it was strikingly clear that after the introduction of ITNs, the proportion of human contact occurring indoors was reduced as contact occurring outdoors in the early evening proportionally increased (Figure 3). This change was evident in both taxa, but was more prominent for the populations of An. funestus. Regarding An. gambiae s.l. in 1997, the vast bulk of human contact to bites occurred when people were indoors $\left(\pi_{\mathrm{i}}=99.7 \%[\mathrm{se}=0.2]\right)$. After high coverage of untreated nets had been achieved by 2004, the proportion of indoor contact remained similarly high $\left(\pi_{\mathrm{i}}=\right.$ 92.6\% [se $=0.4]$ ). After community-wide use of ITNs was achieved by 2009, the proportion of indoor contact $\left(\pi_{\mathrm{i}}\right)$ with $A n$. gambiae s.l. bites had dropped to $82.0 \%$ (se $=0.8$ ) (Table 2, Figure 4). Regarding An. funestus in 1997, the vast bulk of human contact with bites also occurred with people were indoors $\left(\pi_{\mathrm{i}}=100 \%[\mathrm{se}<0.1]\right)$. By 2004, the proportion of indoor contact $\left(\pi_{\mathrm{i}}\right)$ had slightly, although not significantly, decreased to $76.1 \%$ (se $=6.3)$. By 2009 , the proportion of indoor contact with An. funestus bites $\left(\pi_{\mathrm{i}}\right)$ had dropped to only $50.5 \%$ (se $=4.8$; Table 2 Figure 4$)$. At this point in time, half of human contact with the An. funestus group was occurring outdoors, primarily before 9 pm (Figure 3). The estimates presented in Table 2 were calculated using the binary formula and are very similar to the more subtly calculated estimates (Figure 4) in which biting rates were weighted by the proportion of humans reporting to be indoors and outdoors at that time (Figures 3).

Anopheles gambiae s.l. and the An. funestus group were by far the most important malaria vectors present during all survey years. Regarding An. gambiae s.l., the sibling species complex was predominated by An. gambiae s.s. in 1997 and 2004 [3]; however, by 2009 the sibling species composition had shifted to be predominated by $A n$. arabiensis (99.5\%; 849/854 of successful PCR amplifications). Only five individuals were positively identified as $A n$. gambiae s.s. and these mosquitoes were all caught between $10 \mathrm{pm}$ and $5 \mathrm{am}$. Although no longitudinal data were available for Njage village, a shift in An. gambiae s.l. sibling species composition has been observed in Lupiro (Figure 5). The longitudinal shift in sibling species composition towards $A n$. arabiensis was statistically associated with year $(\beta=-1.152$, se $=0.038$, $\mathrm{p}<0.0001$ ), but was not related to rainfall (climate) patters $\left(\beta=-3.079 \times 10^{-4}\right.$, se $\left.=2.044 \times 10-4, \mathrm{p}=0.132\right)$. Unfortunately no historical information regarding the sibling species composition of the An. funestus group is available, but subsequent follow up surveys and successful PCR amplifications of 233 specimens in March 2010 confirmed that the vast majority $(96.6 \% ; n=225)$ of these were $A n$. funestus sensu stricto with the small remainder being $A n$. rivolurum (3.4\%; Okumu et al. Unpublished data). 


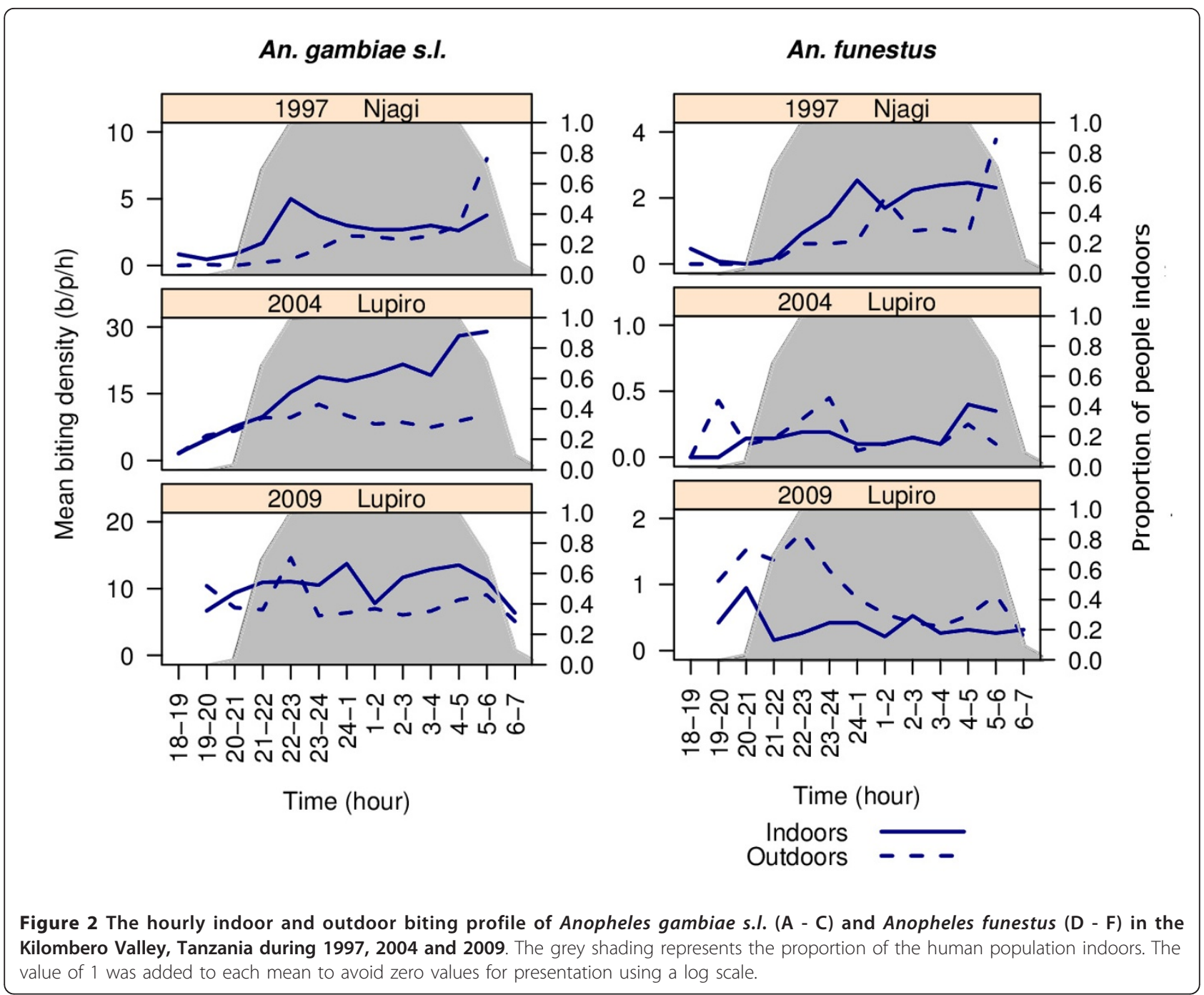

\section{Discussion}

These observations from a previously hyper-endemic setting demonstrate that community-wide ITN use can alter vector populations and reduce the epidemiological importance of indoor-biting mosquitoes. This is consistent with the knowledge that ITNs can reduce the mean density, survival, infectiousness and fitness of mosquito populations [6-9] as a direct function of the proportion of human contact to the vector occurring indoors $[36,39]$. This analysis was conducted retrospectively, based on the fortuitous availability of complementary data from unrelated studies over the years, rather than datasets collected and specifically tailored to examine trends in both the absolute intensity of transmission and the proportions of it which occurred indoors and outdoors. Unfortunately, no longitudinal, year-round, demographically and representatively sampled surveys of human biting mosquitoes in these two specific villages are available from which measures of absolute EIR could be estimated. However, it is likely most that the consistently high ITN use across the entire Kilombero Valley [19] had achieved similarly impressive reductions of EIR in Njage and Lupiro to those observed in the nearby villages of Idete and Namawala where detailed longitudinal entomological studies have been undertaken since 1990 [22]. Thus, the observations in the current study refer to one of the key mechanisms by which residual transmission could be maintained in communities using ITNs where the overall transmission intensity has been dramatically reduced. It is important to note that, the observed changes in feeding patterns are a consequence of killing vector mosquitoes, should not undermine confidence in ITN use, as they are an indicator of successful control. This is supported by recent theoretical models which demonstrate that an attenuated, but nevertheless valuable, amount of personal plus communal protection is provided by ITNs even when the proportion of contact that occurs indoors drops to $50 \%$, as reported here 
Table 1 The proportion (bites per person per night) of mosquitoes caught indoors and during sleeping hours during 1997, 2004 and 2009

\begin{tabular}{|c|c|c|c|c|}
\hline Year & Proportion \pm s.e. & $n / N^{a, b}$ & Odds ratio $[95 \% \mathrm{Cl}]$ & $p$ value \\
\hline \multicolumn{5}{|c|}{ Endophagy $^{\mathrm{a}}$} \\
\hline \multicolumn{5}{|c|}{ Anopheles gambiae s.l. } \\
\hline $1997^{c}$ & $0.585 \pm 0.019$ & $394 / 674$ & 1.00 & NA \\
\hline 2004 & $0.660 \pm 0.006$ & $3,916 / 5,931$ & $1.113[0.887-1.395]$ & 0.354 \\
\hline 2009 & $0.575 \pm 0.008$ & $2,390 / 4,160$ & $0.970[0.770-1.221]$ & 0.796 \\
\hline \multicolumn{2}{|c|}{ Overall influence of Year } & $6,700 / 10,765$ & NA & 0.248 \\
\hline \multicolumn{5}{|c|}{ Anopheles funestus } \\
\hline $1997^{c}$ & $0.608 \pm 0.025$ & $217 / 357$ & 1.00 & NA \\
\hline 2004 & $0.463 \pm 0.055$ & $38 / 82$ & $0.726[0.461-1.142]$ & 0.166 \\
\hline 2009 & $0.298 \pm 0.027$ & $86 / 288$ & $0.455[0.323-0.641]$ & $<0.0001$ \\
\hline \multicolumn{2}{|c|}{ Overall influence of Year } & $341 / 727$ & NA & 0.0001 \\
\hline \multicolumn{5}{|c|}{ Nocturnality ${ }^{\mathrm{b}}$} \\
\hline \multicolumn{5}{|c|}{ Anopheles gambiae s.l. } \\
\hline $1997^{c}$ & $0.957 \pm 0.008$ & $645 / 674$ & 1.00 & NA \\
\hline 2004 & $0.902 \pm 0.004$ & $5,347 / 5,931$ & $0.942[0.840-1.056]$ & 0.305 \\
\hline 2009 & $0.794 \pm 0.006$ & $3,303 / 4,160$ & $0.829[0.738-0.933]$ & 0.0018 \\
\hline \multicolumn{2}{|c|}{ Overall influence of Year } & $9,295 / 10,765$ & NA & $<0.0001$ \\
\hline \multicolumn{5}{|c|}{ Anopheles funestus } \\
\hline $1997^{c}$ & $0.980 \pm 0.007$ & $350 / 357$ & 1.00 & NA \\
\hline 2004 & $0.829 \pm 0.042$ & $68 / 82$ & $0.846[0.594-1.208]$ & 0.354 \\
\hline 2009 & $0.704 \pm 0.027$ & $203 / 288$ & $0.719[0.570-0.907]$ & 0.0054 \\
\hline \multicolumn{2}{|c|}{ Overall influence of Year } & $621 / 727$ & NA & 0.0200 \\
\hline
\end{tabular}

Proportions for each survey period are compared using GLMMs with a binomial distribution, a categorical explanatory variable for study year and a random factor for date.

a Proportion of mosquitoes caught indoors calculated as: $\left(\mathrm{I}_{18 \rightarrow 06} \mathrm{hrs}\right) /\left(\mathrm{I}_{18 \rightarrow 06} \mathrm{hrs}+\mathrm{O}_{18 \rightarrow 06} \mathrm{hrs}\right)$.

${ }^{b}$ Proportion of mosquitoes caught during hours when most people are asleep calculated as: $\left(\mathrm{I}_{21 \rightarrow 05} \mathrm{hrs}+\mathrm{O}_{21 \rightarrow 05} \mathrm{hrs}\right) /\left(\mathrm{I}_{18 \rightarrow 06} \mathrm{hrs}+\mathrm{O}_{18 \rightarrow 06} \mathrm{hrs}\right)$.

c Formed the reference category for the GLMM.

for An. funestus [36]. Nonetheless, in such situations, any residual transmission will be predominantly maintained by a population of mosquitoes that, biting outdoors at dusk and dawn, may respond poorly to further measures targeted inside houses. The existence of shifting feeding patterns obviously hinders efforts to eliminate malaria with current proven methods, but also reflects encouraging success where the impact that can be obtained with ITNs or IRS is pushed to the limits of what is realistically achievable [39].

It was not possible to contrast these results with a comparison site without ITNs, and such a study would be ethically inappropriate in Tanzania or any other country where ITN access and use is rapidly increasing. Nevertheless, a very plausible case [40] is presented that correlates community-wide ITN use with significant changes in the biting profile of the principal malaria vectors. The human-biting behaviour of vectors in this part of Africa appears to independent of population density for these species [41]. This indicates that the observed variations in density, which are natural fluctuations due to seasonality or locality, would have had minimal bias on the observed shifts in behaviour.
Although other environmental and anthropogenic factors may have influenced the mosquito biting behaviour, the differences recorded over time were significant enough that even mild confounding is unlikely to change the overall conclusions. In the current study, the longitudinal influence of rainfall on sibling species composition was quantified and it was observed that climate had not been significantly altered during the study period. Possible anthropogenic confounders include changes in land-use or human behaviour. With time, the population and geographic size of the villages did increase. However, the times at which the population entered and exited houses for sleep during the night remained similar.

Shifts in the sibling species composition are the most likely factor contributing to the observed changes in biting patterns for An. gambiae s.l. The use of ITNs in the study area [Figure 5, [22]] and in other contemporary settings [42] has resulted in a more dramatic drop in the density of highly anthropophagic and endophagic An. gambiae s.s. relative to the zoophagic and adaptable An. arabiensis. Regarding the An. funestus group, An. funestus s.s. was still the predominant species. However, 


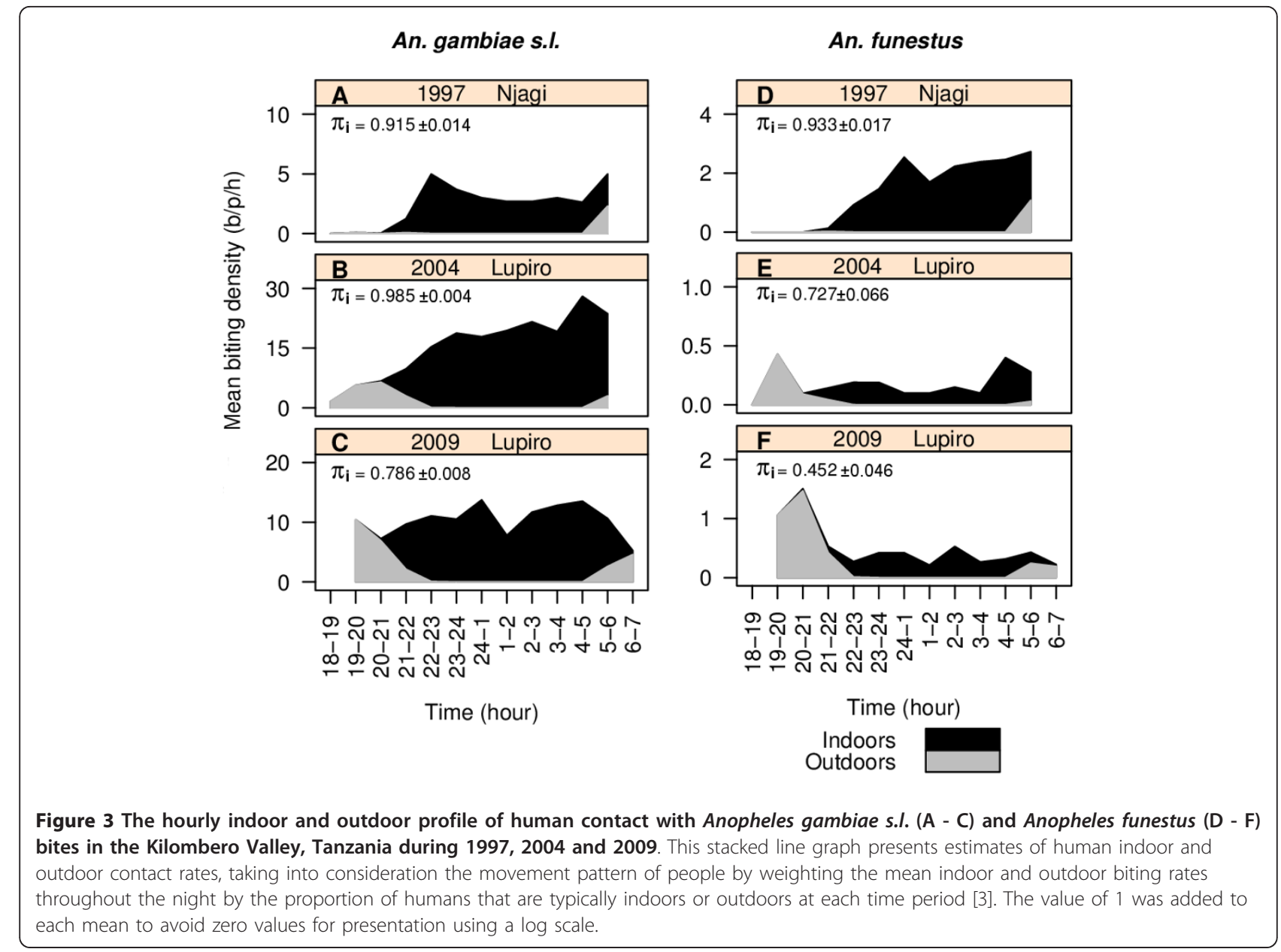

Table 2 The proportion of human contact with mosquito bites occurring indoors $\left(\pi_{i}\right)$ in the Kilombero Valley, Tanzania during 1997, 2004 and 2009

\begin{tabular}{|c|c|c|c|c|}
\hline Year & $\begin{array}{l}\text { Proportion } \pm s \text {. } \\
\text { e. }\end{array}$ & $n / N^{a}$ & $\begin{array}{l}\text { Odds ratio }[95 \% \\
\mathrm{Cl}]\end{array}$ & $\begin{array}{l}p \\
\text { value }\end{array}$ \\
\hline \multicolumn{5}{|c|}{ Anopheles gambiae s.I. } \\
\hline $1997^{\mathrm{b}}$ & $0.997 \pm 0.002$ & $366 / 367$ & 1.00 & NA \\
\hline 2004 & $0.926 \pm 0.004$ & $\begin{array}{l}3,622 / \\
3,912\end{array}$ & $0.928[0.797-1.080]$ & 0.337 \\
\hline 2009 & $0.820 \pm 0.008$ & $\begin{array}{l}1,964 / \\
2,395\end{array}$ & $0.822[0.703-0.962]$ & 0.0143 \\
\hline Overall & I influence of Year & $\begin{array}{l}5,952 / \\
6,674\end{array}$ & NA & 0.0019 \\
\hline \multicolumn{5}{|c|}{ Anopheles funestus } \\
\hline $1997^{\mathrm{b}}$ & $1.000 \pm 0.000$ & $210 / 210$ & 1.00 & NA \\
\hline 2004 & $0.761 \pm 0.063$ & $35 / 46$ & $0.761[0.471-1.229]$ & 0.264 \\
\hline 2009 & $0.505 \pm 0.048$ & $54 / 107$ & $0.504[0.345-0.737]$ & 0.0004 \\
\hline Overall & I influence of Year & $299 / 363$ & NA & 0.0014 \\
\hline
\end{tabular}

Proportions for each survey period are compared using GLMMs with a binomial distribution, a categorical explanatory variable for study year and a random factor for date.

a Calculated as: $\left(\mathrm{I}_{21 \rightarrow 05} \mathrm{hrs}\right) /\left(\mathrm{I}_{21 \rightarrow 05} \mathrm{hrs}+\mathrm{O}_{18,19,20,06 \mathrm{hrs}}\right)$.

${ }^{\mathrm{b}}$ Formed reference category for GLMM. historical reports from IRS campaigns suggest that for this species group, true species replacement [43] can occur with highly anthropophagic, endophagic An. funestus s.s. being replaced by Anopheles parensis or Anopheles rivulorum, which are far less potent vectors $[28,44,45]$. Contemporary examples of changing vector population composition resulting from widespread ITN use in rural Tanzania and Kenya [22,42], and similar historical observations associated with IRS [28,43-45], suggest that such shifts in vector composition may increasingly become the rule rather than the exception for African communities as coverage with one, or both, of these measures increases.

Regarding An. funestus s.s., density changes and/or behavioural avoidance could underlie the biting time shifts of this species. ITN use creates a stressful environment that has reduced the density of indoor biting mosquitoes, which in turn could lead to selection of resistant phenotypes [46]. Prolonged and wide-spread use of ITNs could, thereby, favour traits such as biting outdoors or early in the evening; these traits may be expressed by way of phenotypic plasticity or if these 


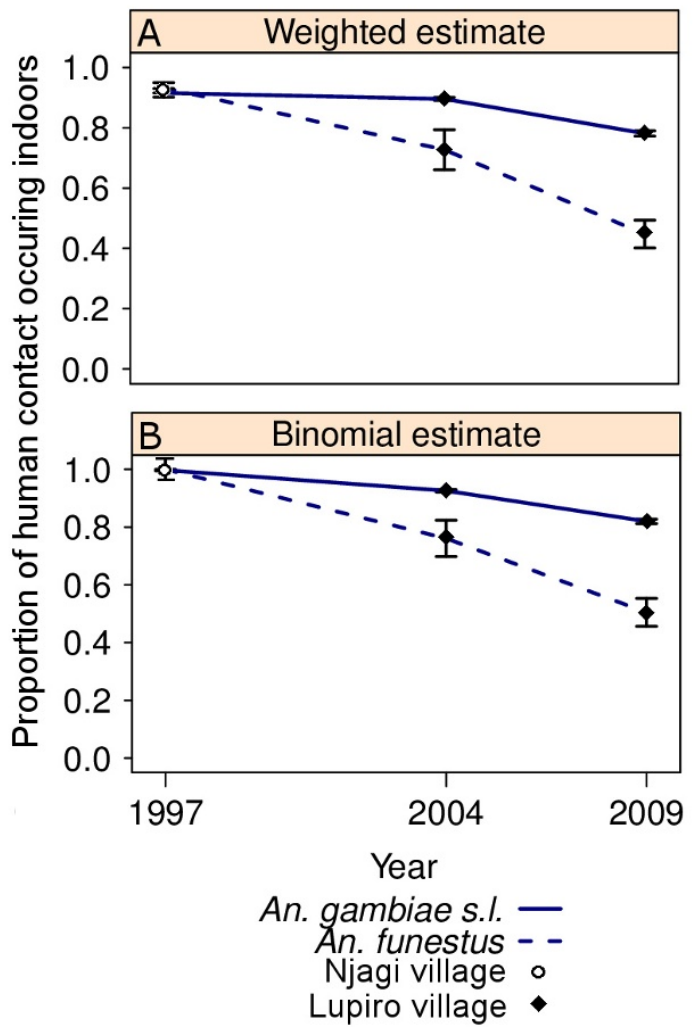

Figure 4 Graphical comparison of the historical and recent estimates of the proportion of human contact with Anophelines occurring indoors $\left(\boldsymbol{\pi}_{\mathbf{i}}\right)$. The proportion of human contact with mosquito bites occurring indoor $\left(\pi_{\mathrm{i}}\right)$ was calculated by taking into consideration the movement pattern of people using two methods: (A) by weighting the mean indoor and outdoor biting rates throughout the night by the proportion of humans that are typically indoors or outdoors at each time period and (B) using the formula: $\left(\mathrm{I}_{21 \rightarrow 05} \mathrm{hrs}\right) /\left(\mathrm{I}_{21 \rightarrow 05} \mathrm{hrs}+\mathrm{O}_{05 \rightarrow 21 \mathrm{hrs}}\right)$.

traits have a genetic basis, they may be selected to increase in frequency in a population [46]. The selection of behavioural traits is difficult to detect, but changes in mosquito biting behaviour have been shown to be immediately and directly induced by vector control tools, especially when excito-repellent insecticides are used [3].

As indoor interventions successfully eliminate the mosquitoes responsible for the majority of transmission, secondary sources of transmission-i.e. outdoor biting mosquitoes-will become culpable for a greater proportion of the declining overall rate of human infections than before. These outdoor-biting mosquitoes respond poorly to further insecticidal measures within houses. Additional vector control tools which target outdoor biting mosquitoes at the adult or immature stages are required to complement ITNs and IRS. This need for complementary

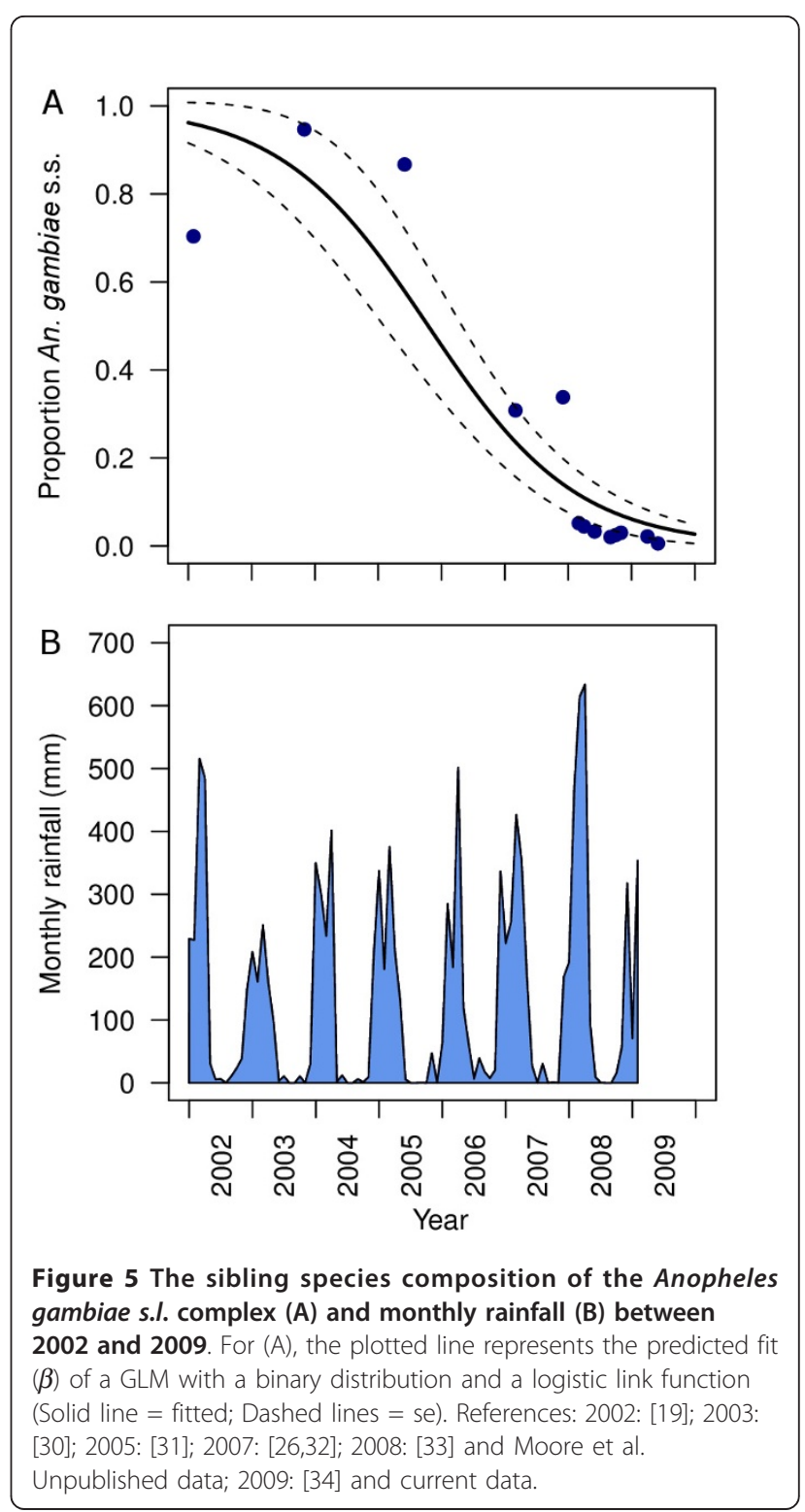

tools and a reprioritisation of research funding is supported by recent reviews [47] and models [39] suggesting that intra-domicilary tools alone are insufficient to drive the parasite prevalence towards elimination in much of the malarious tropics, Africa in particular. Complementary tools, such as repellents [48,49], larval control $[50,51]$ or zooprophylaxis [52], might be used to further suppress malaria transmission by providing personal-protection or reducing the survival, fitness and transmission potential of vector populations.

\section{Abbreviations}

ITN: insecticide treated net; IRS: indoor residual spraying; HLC: human landing catch; GLMM: generalized linear mixed model; $\pi_{i}$ : proportion of human contact to mosquito bites occurring indoor; $\mid \mathrm{HI}$ : Ifakara Health Institute. 


\section{Acknowledgements}

The authors thank all of the volunteers who participated in the study as well as the community of Lupiro village for their continued support. We thank the staff at the Ifakara Health Institute especially Hassan Ngonyani and Robert Sangusangu for technical assistance in conducting entomological surveillance, Nuru Nchimbi and Daniel Lugiko for data entry as well as Alex N. John, Deogratus R. Kavishe, Francis Allen and Mohamed Dangaya for assistance with molecular analysis. We are especially grateful for technical assistance provided by Jason D. Moore when setting up the field site. This work was funded by the Bill \& Melinda Gates Foundation through the Malaria Transmission Consortium, coordinated by Professor Frank Collins and Dr Neil Lobo at Notre Dame University (Award 45114) and the Spatial Repellents as Replacements for DDT project coordinated by Dr Sarah Moore (Award 51431) as well as a Research Career Development Fellowship provided to GFK by the Wellcome Trust (Award 076806). The funders had no role in study design, data collection and analysis, decision to publish, or preparation of the manuscript.

\section{Author details}

'Ifakara Health Institute, Biomedical and Environmental Thematic Group, P.O. Box 53, Ifakara, Tanzania. 'Liverpool School of Tropical Medicine, Vector Group, Pembroke Place, Liverpool, L3 5QA, UK. ${ }^{3}$ The University of Queensland, School of Population Health, Australian Centre for Tropical and International Health, Brisbane, 4006, Australia. ${ }^{4}$ London School of Hygiene and Tropical Medicine, Department of Infectious and Tropical Diseases, Keppel Street, London, WC1E 7HT, UK. ${ }^{5}$ Centers for Disease Control and Prevention, Division of Parasitic Diseases and Malaria, Atlanta, Georgia, USA.

\section{Authors' contributions}

Conceived and designed the experiments: GFK (2004 and 2009), CJD (1997). Performed the experiments: TLR, NJG. Analysed the data and wrote the manuscript: TLR, GFK. Reviewed the manuscript: NJG, CJD, SPK. All authors have read and approved the final manuscript.

\section{Competing interests}

The authors declare that they have no competing interests.

Received: 20 January 2011 Accepted: 9 April 2011

Published: 9 April 2011

\section{References}

1. Cohuet A, Harris C, Robert V, Fontenille D: Evolutionary forces on Anopheles: what makes a malaria vector? Trends Parasitol 2010, 26:130-136.

2. Pates H, Curtis C: Mosquito behavior and vector control. Annu Rev Entomol 2005, 50:53-70.

3. Killeen GF, Kihonda J, Lyimo E, Oketch FR, Kotas ME, Mathenge E, Schellenberg JA, Lengeler C, Smith TA, Drakeley CJ: Quantifying behavioural interactions between humans and mosquitoes: evaluating the protective efficacy of insecticidal nets against malaria transmission in rural Tanzania. BMC Infect Dis 2006, 6:161.

4. Lyimo IN, Ferguson HM: Ecological and evolutionary determinants of host species choice in mosquito vectors. Trends Parasitol 2009, 25:189-196.

5. Lengeler C: Insecticide-treated bednets and curtains for preventing malaria (Review). Cochrane Database Syst Rev 2004, 2:CD000363.

6. Gimnig JE, Vulule JM, Lo TQ, Kamau L, Kolczak MS, Phillips-Howard PA, Mathenge EM, Ter Kuile FO, Nahlen BL, Hightower AW: Impact of permethrin-treated bed nets on the entomologic indicies in an area of intense year-round malaria transmission. Am J Trop Med Hyg 2003, 68:16-22.

7. Lines JD, Myamba J, Curtis CF: Experimental hut trials of permethrinimpregnated mosquito nets and eave curtains against malaria vectors in Tanzania. Med Vet Entomol 1987, 1:37-51.

8. Miller JE, Lindsay SW, Armstrong JR: Experimental hut trials of bednets impregnated with synthetic pyrethroid or organophosphate insecticide for mosquito control in The Gambia. Med Vet Entomol 1991, 5:465-476.

9. Lindsay SW, Adiamah JH, Miller JE, Armstrong JRM: Pyrethroid-treated bednet effects on mosquitoes of the Anopheles gambiae complex in The Gambiae. Med Vet Entomol 1991, 5:477-483.
10. Killeen GF, Smith TA, Ferguson HM, Abdulla S, Mshinda H, Lengeler C, Kachur SP: Preventing childhood malaria in Africa by protecting adults from mosquitoes with insecticide treated-nets. PLoS Med 2007, 4:e229.

11. Maxwell CA, Msuya E, Sudi M, Njunwa K, Carneiro IA, Curtis CF: Effect of community-wide use of insecticide-treated nets for 3-4 years on malarial morbidity in Tanzania. Trop Med Int Health 2002, 7:1003-1008.

12. Hawley WA, Phillips-Howard PA, Ter Kuile FO, Terlouw DJ, Vulule JM, Ombok M, Nahlen BL, Gimnig JE, Kariuki SK, Kolczak MS: Community-wide effects of permethrin-treated bed nets on child mortality and malaria morbidity in Western Kenya. Am J Trop Med Hyg 2003, 68:121-127.

13. Binka FN, Indome F, Smith T: Impact of spatial distribution of permethrinimpregnated bed nets on child mortality in rural northern Ghana. Am J Trop Med Hyg 1998, 59:80-85.

14. O'Meara WP, Mangeni JN, Steketee R, Greenwood B: Changes in the burden of malaria in sub-Saharan Africa. Lancet Infect Dis 2010, 10:545-555.

15. D'Acremont V, Lengeler C, Genton B: Reduction in the proportion of fevers associated with Plasmodium falciparum parasitaemia in Africa: a systematic review. Malar J 2010, 9:240.

16. Ceesay SJ, Casals-Pascual C, Nwakanma DC, Walther M, Gomez-Escobar N, Fulford AJC, Takem EN, Nogaro S, Bojang KA, Corrah T, Jaye MC, Taal MA, Sonko AAJ, Conway DJ: Continued decline of malaria in The Gambia with implications for elimination. PLOS ONE 2010, 5:e12242.

17. Feachem RGA, Phillips AA, Hwang J, Cotter C, Wielgosz B, Greenwood BM, Sabot O, Rodriguez MH, Abeyasinghe RR, Ghebreyesus TA, Snow RW: Shrinking the malaria map: progress and prospects. Lancet 2010, 376:1566-1578.

18. Armstrong Schellenberg JRM, Abdulla S, Nathan R, Mukasa O, Marchant TJ, Kikumbih N, Mushi AK, Mponda H, Minja H, Mshinda H, Tanner M, Lengeler C: Effect of large-scale social marketing of insecticide-treated nets on child survival in rural Tanzania. Lancet 2001, 357:1241-1247.

19. Killeen GF, Tami A, Kihonda J, Okumu FO, Kotas ME, Grundmann H, Kasigudi N, Ngonyani H, Mayagaya V, Nathan R, Abdulla S, Charlwood JD, Smith TA, Lengeler C: Cost-sharing strategies combining targeted public subsidies with private-sector delivery achieve high bednet coverage and reduced malaria transmission in Kilombero Valley, southern Tanzania. BMC Infect Dis 2007, 7:121.

20. Ng'habi KRN: Behavioural, ecological and genetic determinants of mating and gene flow in Africa malaria mosquitoes. PhD Thesis PhD Thesis Wageningen University; 2010.

21. Magesa SM, Lengeler C, deSavigny D, Miller JE, Njau RJ, Kramer K, Kitua A, Mwita A: Creating an "enabling environment" for taking insecticide treated nets to national scale: the Tanzanian experience. Malar J 2005, 4:32.

22. Russell TL, Lwetiojera DW, Maliti D, Chipwaza B, Kihonda J, Charlwood JD, Smith TA, Lengeler C, Mwanyangala MA, Nathan R, Knols BGJ, Takken W, Killeen GF: Impact of promoting longer-lasting insecticide treatment of bednets upon malaria transmission in a rural Tanzanian setting with pre-existing high coverage of untreated nets. Malar J 2010, 9:187.

23. Charlwood JD, Vij R, Billingsley PF: Dry season refugia of malariatransmitting mosquitoes in a dry savannah zone of east Africa. Am J Trop Med Hyg 2000, 62:726.

24. Anderson RA, Knols BGJ, Koella JC: Plasmodium falciparum sporozoites increase feeding-associated mortality of their mosquito hosts Anopheles gambiae s.l. Parasitol 2000, 120:329-333.

25. Silver JB: Mosquito ecology: field sampling methods. New York: Springer ${ }^{\prime \prime}$ Third 2008.

26. Ogoma SB, Lweitoijera DW, Ngonyani H, Furer B, Russell TL, Mukabana WR, Killeen GF, Moore SJ: Screening mosquito house entry points as a potential method for integrated control of endophagic filariasis, arbovirus and malaria vectors. PLoS Negl Trop Dis 2010, 4:e773.

27. Gillies MT, Coetzee M: A supplement to the Anophelinae of Africa south of the Sahara (Afrotropical region). Johannesburg: South African Institute for Medical Research; 1987.

28. Gillies MT, De Meillon B: The Anophelinae of Africa south of the Sahara (Ethiopian Zoogeographical Region). Johannesburg: South African Institute for Medical Research; 1968.

29. Scott JA, Brogdon WG, Collins FH: Identification of single specimens of the Anopheles gambiae complex by the polymerase chain reaction. Am J Trop Med Hyg 1993, 49:520-529. 
30. Scholte EJ: The entomopathogenic fungus Metarhizium anisopliae for mosquito control: impact on the adult stage of the African malaria vector Anopheles gambiae and filariasis vector Culex quinquefasciatus. PhD Thesis Wageningen University; 2004.

31. Huho BJ, Ng'habi KR, Killeen GF, Nkwenguilia G, Knols BGJ, Ferguson HM: Nature beats nurture: a cast study of the physiological fitness of freeliving and laboratory-reared male Anopheles gambiae s.l. J Exp Biol 2007, 210:2939-2947.

32. Ng'habi KR, Meneses CR, Cornel AJ, Slotman MA, Knols BGJ, Ferguson HM, Lanzaro GC: Clarification of anomalies in the application of a 2La molecular karyotyping method for the malaria vector Anopheles gambiae. Parasit Vectors 2008, 1:45.

33. Govella NJ, Moore JD, Killeen GF: An exposure-free tool for monitoring adult malaria mosquito populations. Am J Trop Med Hyg 2010, 83:596-600.

34. Okumu FO, Killeen GF, Ogoma S, Biswaro L, Smallegange RC, Mbeyela E, Titus E, Munk C, Ngonyani H, Takken W, Mshinda H, Mukabana WR, Moore SJ: Development and field evaluation of a synthetic mosquito lure that is more attractive than humans. PLOS ONE 2010, 5:e8951.

35. Koekemoer LL, Kamau L, Hunt RH, Coetzee M: A cocktail polymerase chain reaction assay to identify members of the Anopheles funestus (Diptera: Culicidae) group. Am J Trop Med Hyg 2002, 6:804-811.

36. Govella NJ, Okumu FO, Killeen GF: Insecticide-treated nets can reduce malaria transmission by mosquitoes which feed outdoors. Am J Trop Med Hyg 2010, 82:415-419.

37. Lindsay SW, Parson L, Thomas CJ: Mapping the range and relative abundance of the two principal African malaria vectors, Anopheles gambiae sensu stricto and An. arabiensis, using climate data. Proceedings of the Royal Society of London Series B: Biological Sciences 1998, 265:847-854.

38. The R project for statistical computing. 2009 [http://www.r-project.org/.]

39. Griffin JT, Hollingsworth TD, Okell LC, Churcher TS, White M, Hinsley W, Bousema T, Drakeley CJ, Ferguson NM, Basáñez M-G, Ghani AC: Reducing Plasmodium falciparum malaria transmission in Africa: a model-based evaluation of intervention strategies. PLOS Med 2010, 7:e1000324.

40. Habicht JP, Victora CG, Vaughan JP: Evaluation designs for adequacy, plausibility and probability of public health programme performance and impact. Int J Epidemiol 1999, 28:10-18.

41. Charlwood JD, Smith T, Kihonda J, Heiz B, Billingsley PF, Takken W: Density independent feeding success of malaria vectors (Diptera: Culicidae) in Tanzania. Bull Entomol Res 1995, 85:29-35.

42. Bayoh MN, Mathias D, Odiere M, Mutuku F, Kamau L, Gimnig J, Vulule J, Hawley W, Hamel M, Walker E: Anopheles gambiae: historical population decline associated with regional distribution of insecticide-treated bed nets in western Nyanza Province, Kenya. Malar J 2010, 9:62.

43. Lounibos LP: Competitive displacement and reduction. Bull AMCA 2007, 23:276-282.

44. Gillies MT, Smith A: The effect of a residual house-spraying campaign in East Africa on species balance in the Anopheles funestus group. The replacement of $A$. funestus Giles by A. rivulorum Leeson. Bull Entomol Res 1960, 51:243-252.

45. Gillies MT, Furlong M: An investigation into the behaviour of Anopheles parensis Gillies at Malindi on the Kenya coast. Bull Entomol Res 1964, 55:1-16.

46. Badyaev AV: Stress-induced variation in evolution: from behavioural plasticity to genetic assimilation. Proc R Soc Lond B 2005, 272:877-886.

47. Ferguson HM, Dornhaus A, Beeche A, Borgemeister C, Gottlieb M, Mulla MS, Gimnig JE, Fish D, Killeen GF: Ecology: a prerequisite for malaria elimination and eradication. PLOS Med 2010, 7:e1000303.

48. Frances SP, Wirtz RA: Repellents: past, present, and future. J Am Mosa Control Assoc 2005, 21:1-3.

49. Durrheim DN, Govere JM: Malaria outbreak control in an African village by community application of 'deet' mosquito repellent to ankles and feet. Med Vet Entomol 2002, 16:112-115.

50. Killeen GF, Fillinger U, Knols BG: Advantages of larval control for African malaria vectors: Low mobility and behavioral responsiveness of immature mosquito stages allow high effective coverage. Malar J 2002, $1: 8$

51. Fillinger U, Lindsay SW: Suppression of exposure to malaria vectors by an order of magnitude using microbial larvicides in rural Kenya. Trop Med Int Health 2006, 11:1-14.
52. Saul A: Zooprophylaxis or zoopotentiation: the outcome of introducing animals on vector transmission is highly dependent on the mosquito mortality while searching. Malar J 2003, 2:32.

doi:10.1186/1475-2875-10-80

Cite this article as: Russell et al: Increased proportions of outdoor feeding among residual malaria vector populations following increased use of insecticide-treated nets in rural Tanzania. Malaria Journal 2011 10:80.

\section{Submit your next manuscript to BioMed Central and take full advantage of:}

- Convenient online submission

- Thorough peer review

- No space constraints or color figure charges

- Immediate publication on acceptance

- Inclusion in PubMed, CAS, Scopus and Google Scholar

- Research which is freely available for redistribution

Submit your manuscript at www.biomedcentral.com/submit
C Biomed Central 